\title{
Prominent Nucleoli and Non-glandular Feature Are Independent Predictors of PD-L1 Expression in Lung Adenocarcinoma
}

\author{
NARA YOON ${ }^{1}$, JIYOUNG KIM $^{1}$, LEE-SO MAENG ${ }^{1}$, JOONG HYUN AHN $^{2}$ and EUN SU PARK ${ }^{1}$ \\ ${ }^{1}$ Department of Pathology, Incheon St. Mary's Hospital, College of Medicine, \\ The Catholic University of Korea, Incheon, Republic of Korea; \\ ${ }^{2}$ Division of Pulmonary, Allergy and Critical Care Medicine, Department of Internal Medicine, \\ Incheon St. Mary's Hospital, College of Medicine, The Catholic University of Korea, Incheon, Republic of Korea
}

\begin{abstract}
Background/Aim: In patients with non-small cell lung cancer, relationships between PD-L1 (programmed deathligand 1) expression and clinicopathological characteristics have been examined. However, the association between cytological features and PD-L1 expression remains unknown. Thus, the aim of this study was to investigate whether nuclear features might be correlated with PD-L1 expression in patients with advanced and inoperable lung adenocarcinoma using small biopsy specimens. Materials and Methods: Archived slides from 90 patients with lung adenocarcinoma who underwent small biopsy between October 2014 and May 2017 at the Incheon St. Mary's Hospital, were reviewed. PD-L1 expression was detected by immunohistochemistry using $P D$ L1 22C3 IHC assay. Associations of PD-L1 expression with pathological and molecular features (EGFR mutation, ALK and ROS-1 rearrangement) were statistically analyzed. Results: $P D-L 1$ expression in tumor cells was positive in 33 of 90 cases (36.7\%). Higher PD-L1 expression ( $\geq 50 \%$ ) was more frequent in cases with marked nuclear pleomorphism $(p<0.001)$, coarse chromatin pattern $(p=0.006)$, predominant nucleoli $(\geq 3 \mu \mathrm{m})$ $(p<0.001)$, large nuclear diameter $(>5 \times$ small lymphocyte $)$ $(p=0.006)$, non-glandular feature $(p<0.001)$, and atypical mitosis $(p=0.034)$. There were no significant correlations between PD-L1 positivity and molecular features. In multivariable logistic regression analysis, $P D-L 1$ positivity was independently associated with prominent nucleoli $(p=0.005)$ and non-glandular feature ( $p=0.007)$. Conclusion: Prominent nucleoli and non-glandular feature are independent predictors of PD-L1 expression in lung adenocarcinoma.
\end{abstract}

Correspondence to: Eun Su Park, Department of Pathology, Incheon St. Mary's Hospital, College of Medicine, The Catholic University of Korea, 56 Dong soo-ro Bupyeong-gu, Incheon 21431, Republic of Korea. Tel: +82 322805517, e-mail: espark78@gmail.com

Key Words: Programmed cell death 1 ligand 1, non-small cell lung cancer, adenocarcinoma, cell nucleoli.
Lung cancer is the leading cause of cancer-related death worldwide (1). Recently, immunotherapy has received great attention in cancer therapy. Programmed death-ligand 1 (PDL1) expression became a distinct biomarker to determine whether non-small cell lung cancer (NSCLC) patients will respond to anti-PD-1/PD-L1 therapies $(2,3)$. PD-1 is the receptor of PD-L1 and PD-L2 and is expressed on T-cells. It regulates the activation of $\mathrm{T}$ cells following activation by its ligands, PD-L1 and PD-L2, that are expressed in many cancer cells (4). Blockade of the interaction between PD-1 and PDL1/2 by anti-PD-1 or anti-PD-L1 antibodies can induce antitumor immune response. This has been successfully used in the treatment of various types of human cancer including NSCLC (5-8). FDA has recently approved anti- PD-1/PD-L1 antibodies including pembrolizumab as a single agent in first and second line therapy for lung cancer (9). Determining the clinicopathological significance of PD-L1 protein expression would indicate effective treatment strategies for PD-1/PDL1-inhibition by using antibodies. Although there are several studies on the relationships between PD-L1 expression and clinicopathological features (10), the factors that can determine drug responsiveness are not fully understood yet (11). Especially, no studies have reported the association between nuclear features and PD-L1 expression. Therefore, the objective of this study was to evaluate relationships of PD-L1 positivity with several clinical factors and nuclear features in patients with advanced and inoperable lung adenocarcinoma using biopsy samples.

\section{Materials and Methods}

Patients and tissue samples. Ninety patients diagnosed with lung adenocarcinoma who underwent small biopsy between October 2014 and May 2017 at Incheon St. Mary's Hospital were selected. These small biopsy specimens were obtained from lung (52 cases), pleura (16 cases), lymph node (13 cases), brain ( 8 cases), and bone ( 1 cases). Clinical data including age at diagnosis, sex, smoking history, surgical procedure, EGFR mutation status, and ALK and ROS1 rearrangements were retrospectively reviewed based on 
electronic medical records. EGFR status had been determined in tumor tissue using peptide nucleic acid-locked nucleic acid polymerase chain reaction clamp method. ALK and ROS1 rearrangements had been examined by fluorescent in situ hybridization using ZytoVision ALK dual color break apart probe and ZytoVision SPEC ROS1 Dual Color Break Apart Probe.

Ethics statement. This study was approved by the Institutional Review Board of Incheon St. Mary Hospital (ID: OC18RESI0041).

Immunohistochemistry stain. Dako Autostainer Link 48 platform and automated staining protocol that had been validated for PD-L1 IHC $22 \mathrm{C} 3$ pharmDx assay were used for PD-L1 immunostaining according to the manufacturer's instructions $(12,13)$. In brief, deparaffinization, rehydration, and target retrieval were performed by Autostainer Link 48 (Agilent Technologies, Dako, Carpinteria, CA, USA). After incubation with monoclonal mouse anti-human PD-L1 antibody clone $22 \mathrm{C} 3$ or mouse immunoglobulin $\mathrm{G}$ isotype as a negative control reagent, specimens were incubated with anti-mouse linker antibody specific to the host species of the primary antibody followed by incubation with a ready-to-use visualization reagent consisting of secondary antibody molecules and horseradish peroxidase molecules coupled to a dextran polymer backbone. Enzymatic conversion of the subsequently added 3,30-diaminobenzidine tetrahydrochloride chromogen followed by addition of 3,30-diaminobenzidine tetrahydrochloride enhancer that resulted in precipitation of a visible reaction product at the site of antigen. These specimens were then counterstained with haematoxylin and coverslipped.

Interpretation of immunohistochemistry (IHC). All IHC slides were evaluated by two pathologists (ES Park and NR Yoon) blinded to clinical data. In case of disagreement, slides were re-examined until a consensus was achieved.

Carcinoma cells showing membranous staining for PD-L1 were evaluated as positive cells. The proportion of PD-L1 positive cells was estimated as the percentage of total carcinoma cells.

We first set the cut-off value at $50 \%$, which was used in the pembrolizumab clinical trial $(14,15)$. In KEYNOTE-001 trial, PDL1 expression of at least $50 \%$ of tumor cells correlated with improved clinical outcome in NSCLC patients treated with pembrolizumab $(14,15)$. Representative images of PD-L1 staining patterns of tumor specimens are shown in Figure 1.

Histologic evaluation. All available hematoxylin and eosin (H\&E)stained slides were reviewed by a pathologist (ES Park) and problematic cases were reviewed by two pathologists (ES Park and NR Yoon). For each case, nuclear atypia nuclear diameter, nuclear/cytoplasmic (N/C) ratio, chromatin pattern, prominence of nucleoli, intranuclear inclusions, mitotic count, atypical mitoses, and nuclear diameter were evaluated.

The overall nuclear atypia was classified into two categories and recorded as mild to moderate atypia (relatively uniform nuclei) and severe atypia (bizarre, enlarged nuclei of varied sizes, with some nuclei at least twice as large as others). Nuclear/cytoplasmic (N/C) ratio was broken down into the following three categories: low N/C ratio $(<1 / 3$ nucleus to cytoplasm area), intermediate $\mathrm{N} / \mathrm{C}$ ratio $(1 / 3$ $2 / 3$ ), and high N/C ratio ( $>2 / 3)$. Chromatin pattern was divided into two categories: finely granular and coarsely granular. Prominence of nucleoli was evaluated using as a reference nearby small lymphocytes, which measured approximately $3 \mu \mathrm{m}$. It was graded into the following two categories by the measurement of predominant size-1) indistinct: inconspicuous or distinct but small $(<3 \mu \mathrm{m})$ at intermediate-power $(\times 100), 2)$ large, $\geq 3 \mu \mathrm{m}(16)$. Subsequently, for statistical analysis, these groups were consolidated to "indistinct/distinct" versus "large". Intranuclear inclusions were determined as present or absent. Mitotic count was measured by the number of mitoses per a high-power field (HPF) (40x objective). Atypical mitoses were considered present if any was observed. For nuclear diameter, we selected at least 3 HPFs with the largest nuclei and evaluated the average nuclear diameter among at least 100 tumor cells using as reference nearby small lymphocytes and classified it as follows: small nuclei, equal or smaller than five times of small lymphocytes ( $\leq 5 \times$ small lymphocyte); and large nuclei, larger than five times of the small lymphocytes $(>5 x$ small lymphocyte) (17). Architectural features were divided into two categories: glandular (lepidic, papillary and acinar type) and nonglandular type (solid and micropapillary type).

Statistical analysis. Statistical analysis was performed using SPSS statistical software version 20.0 (IBM Corp., Armonk, NY, USA). Clinicopathological associations with PD-L1 expression were analyzed using Chi-square test and logistic regression analysis. A $p$-value $<0.05$ was considered statistically significant.

\section{Results}

Patient population. Clinical characteristics of the patient population $(\mathrm{n}=90)$ are summarized in Table I. There were 50 $(55.6 \%)$ males and $40(44.4 \%)$ females. Fifty-four $(60.0 \%)$ patients were smokers while 36 were never smokers. The mean age of these patients at diagnosis was 67 years (range $=39-87$ years). EGFR status was available for all patients. Of these patients, $54(60.0 \%)$ had wild-type EGFR while $36(40.0 \%)$ had mutant EGFR. There were three cases with ALK rearrangement but no case with ROS1 rearrangement.

Relationship between PD-L1 expression and clinicopathological features. PD-L1 expression in tumor cells was positive in 33 (36.7\%) of 90 cases. Relationships between PD-L1 expression and clinicopathological features are summarized in Table I. Univariate analysis using Chi-square test revealed that PD-L1 expression was not associated with age, smoking, and EGFR status.

Nuclear feature correlation with PD-L1 expression. PD-L1 expression $(\geq 50 \%)$ was more frequent in those with severe nuclear atypia $(p<0.001)$, coarse chromatin pattern ( $p=0.006)$, predominant nucleoli $(\geq 3 \mu \mathrm{m})(p<0.001)$, large nuclear diameter ( $>5$ small lymphocytes) $(p=0.006)$, nonglandular feature $(p<0.001)$, and atypical mitosis $(p=0.034)$. There were no significant correlations between PD-L1 positivity and molecular features. In multivariable logistic regression analysis, PD-L1 positivity was independently associated with prominent nucleoli (multivariable odds ratio: 6.688; 95\% confidence interval $[\mathrm{CI}]: 1.784-25.065 ; p=0.005$ ) and non-glandular feature (multivariable odds ratio: 4.539; 95\% CI=1.508-13.663; $p=0.007$ ) (Table II). 


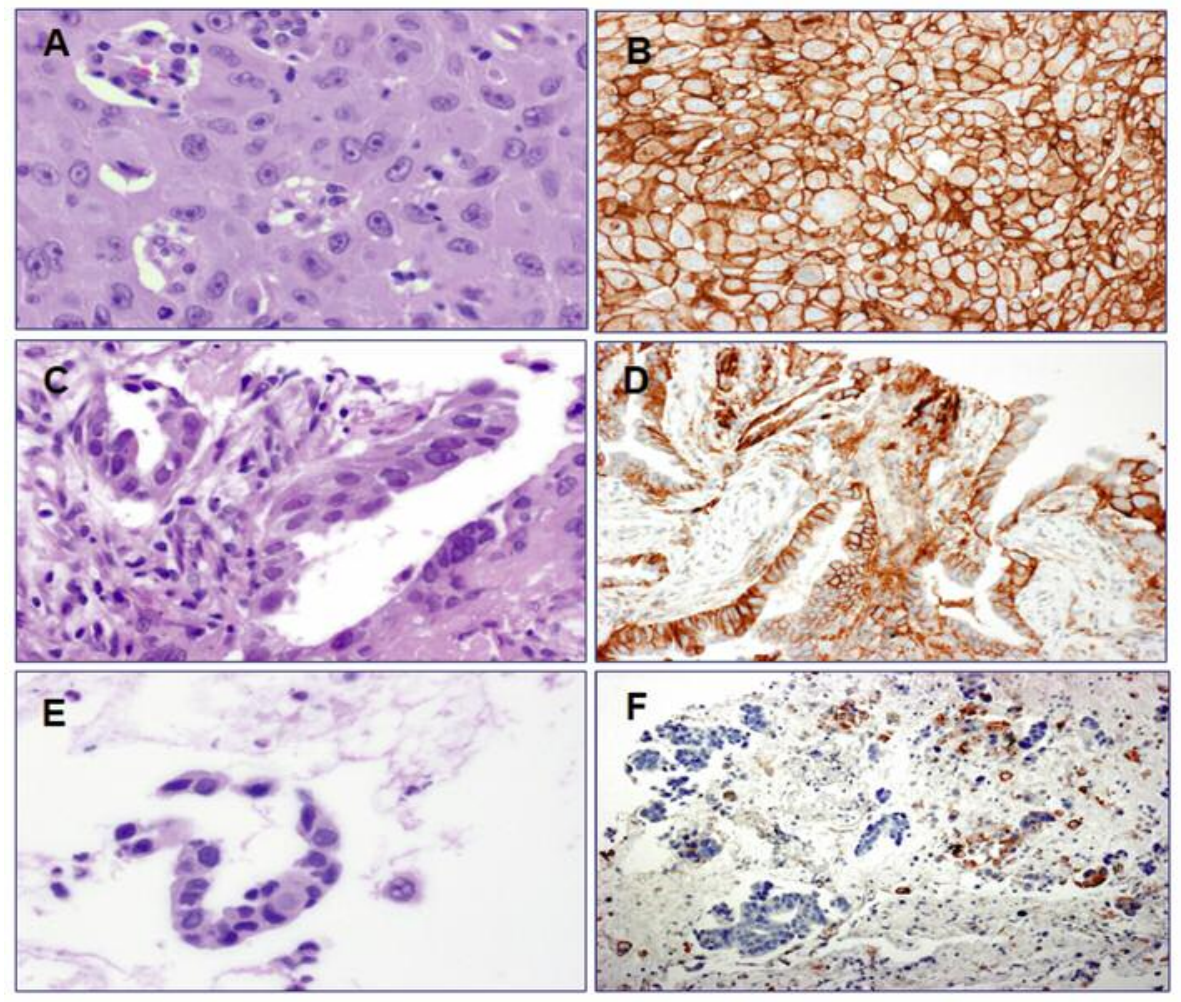

Figure 1. Representative images for histology and PD-L1 expression. The tumor cells with solid structure and prominent nucleoli (A) show diffuse membranous staining of PD-L1 (B). Tumor cells with prominent nucleoli and glandular structure $(C)$ also express PD-L1 (D). In contrast, the tumor cells with indistinct or small nucleoli and glandular structure $(E)$ show no staining of PD-L1 (F). Original magnification: A-E, $\times 400 ; F, \times 200$.

\section{Discussion}

Our results demonstrated that PD-L1 protein expression was associated with worse nuclear features of cancer cells in 90 preoperative biopsy specimens of lung adenocarcinomas. PDL1 was highly expressed in cases showing severe nuclear atypia $(p<0.001)$, coarse chromatin pattern $(p=0.006)$, predominant nucleoli $(\geq 3 \mu \mathrm{m}) \quad(p<0.001)$, large nuclear diameter ( $>5$ small lymphocytes) $(p=0.006)$, non-glandular feature $(p<0.001)$ and atypical mitosis $(p=0.034)$. Further multivariate analysis revealed that prominent nucleoli and nonglandular feature were independent risk factors of PD-L1 expression.

Previous studies have demonstrated that PD-L1 is commonly expressed in clinically and histologically aggressive NSCLC. In adenocarcinoma, Takada et al. have shown that PD-L1 positivity is significantly associated with male gender, smoking, higher tumor grade, advanced $\mathrm{T}$ status, advanced $\mathrm{N}$ status, advanced stage, the presence of pleural and vessel invasions, micropapillary or solid predominant histological subtypes, and wild-type EGFR (10). Their analysis also revealed that smoking, higher pathological grade (micropapillary or solid predominant), and wild-type EGFR were independent predictors of PD-L1 positivity (10). In surgical specimens of lung adenocarcinoma, PD-L1 expression was correlated with solid predominant subtype and high ki-67 labeling index $(18,19)$. Recently, Ng kee Kwong F et al. have reported that NSCLCs with pleomorphic features are associated with high PD-L1 expression (20). However, there is no report uncovering the association between PD-L1 expression and specific nuclear features. Our results confirmed that non-glandular structure and prominent nucleoli were significantly associated with high expression of PD-L1 in small biopsy in both univariate and multivariate analyses. Therefore, non-glandular feature and prominent nucleoli of adenocarcinoma can be surrogate markers for PD-L1 expression in biopsy specimen.

In lung adenocarcinoma, solid predominant subtypes along with micropapillary pattern have been associated with poorer prognosis compared to other subtypes (21-23). Our results demonstrated that PD-L1 expression was independently associated with non-glandular feature in lung adenocarcinoma, supporting previous assumption that PD-L1 expression is correlated with poor-prognosis $(10,20,24)$. In other organs, PD-L1 expression is also known to be related to poor prognostic features. For example, it was associated with larger tumor size, higher nuclear grade, estrogen and 
Table I. Clinopathological features according to PD-L1 expression.

\begin{tabular}{|c|c|c|c|c|}
\hline Variable & All, n (\%) & PD-L1 positive, n (\%) & PD-L1 negative, $\mathrm{n}(\%)$ & $p$-Value \\
\hline Number of cases & $90(100.0)$ & $33(36.7 \%)$ & $57(63.3 \%)$ & \\
\hline Gender & & & & 0.661 \\
\hline Male & $50(55.6 \%)$ & $17(51.5 \%)$ & $33(57.9 \%)$ & \\
\hline Female & $40(44.4 \%)$ & $16(48.5 \%)$ & $24(42.1 \%)$ & \\
\hline Smoking status & & & & 0.505 \\
\hline Never smokers & $36(40 \%)$ & $15(45.5 \%)$ & $21(36.8 \%)$ & \\
\hline Former or current smokers & $54(60 \%)$ & $18(54.5 \%)$ & $36(63.2 \%)$ & \\
\hline Nuclear atypia & & & & $<0.001^{*}$ \\
\hline Mild/moderate & $56(62.2 \%)$ & $11(33.3 \%)$ & $45(78.9 \%)$ & \\
\hline Severe & $34(37.8 \%)$ & $22(66.7 \%)$ & $12(21.1 \%)$ & \\
\hline Chromatin pattern & & & & $0.007 *$ \\
\hline Homogeneous/Fine & $55(61.1 \%)$ & $14(42.4 \%)$ & $41(71.9 \%)$ & \\
\hline Coarse granular & $35(38.9 \%)$ & $19(57.6 \%)$ & $16(28.1 \%)$ & \\
\hline Nuclear/cytoplasmic ratio & & & & 0.646 \\
\hline$<1 / 3$ & $4(4.4 \%)$ & $1(3.0 \%)$ & $3(5.3 \%)$ & \\
\hline $1 / 3-2 / 3$ & $36(40.0 \%)$ & $15(45.5 \%)$ & $21(36.8 \%)$ & \\
\hline$>2 / 3$ & $50(55.6 \%)$ & $17(51.5 \%)$ & $33(57.9 \%)$ & \\
\hline Nucleoli & & & & $<0.001 *$ \\
\hline Indistinct or small distinct $(<3 \mu \mathrm{m})$ & $70(77.8 \%)$ & $17(51.5 \%)$ & $53(93.0 \%)$ & \\
\hline large $(\geq 3 \mu \mathrm{m})$ & $20(22.2 \%)$ & $16(48.5 \%)$ & $4(7.0 \%)$ & \\
\hline Mitotic count & & & & 0.225 \\
\hline $0-1 / \mathrm{HPFs}$ & $57(63.3 \%)$ & $18(54.5 \%)$ & $39(68.4 \%)$ & \\
\hline 2-4/HPFs & $25(27.8 \%)$ & $10(30.3 \%)$ & $15(26.3 \%)$ & \\
\hline$\geq 5$ HPFs & $8(8.9 \%)$ & $5(15.2 \%)$ & $3(5.3 \%)$ & \\
\hline Nuclear diameter & & & & $0.009 *$ \\
\hline$\leq 5$ small lymphocyte & $69(76.7 \%)$ & $20(60.6 \%)$ & $49(86.0 \%)$ & \\
\hline$>5$ small lymphocyte & $21(23.3 \%)$ & $13(39.4 \%)$ & $8(14.0 \%)$ & \\
\hline Atypical mitosis & & & & $0.034 *$ \\
\hline Absence & $80(88.9 \%)$ & $26(78.8 \%)$ & $54(94.7 \%)$ & \\
\hline Presence & $10(11.1 \%)$ & $7(21.2 \%)$ & $3(5.3 \%)$ & \\
\hline Intranuclear inclusion & & & & 0.661 \\
\hline Absence & $51(56.7 \%)$ & $20(60.6 \%)$ & $31(54.4 \%)$ & \\
\hline Presence & $39(43.3 \%)$ & $13(39.4 \%)$ & $26(45.6 \%)$ & \\
\hline Glandular feature & & & & $<0.001 *$ \\
\hline Absence & $61(67.8 \%)$ & $13(39.4 \%)$ & $48(84.2 \%)$ & \\
\hline Presence & $29(32.2 \%)$ & $20(60.6 \%)$ & $9(15.8 \%)$ & \\
\hline EGFR mutation & & & & 0.076 \\
\hline Negative & $54(60.0 \%)$ & $24(72.7 \%)$ & $30(52.6 \%)$ & \\
\hline Positive & $36(40.0 \%)$ & $9(27.3 \%)$ & $27(47.4 \%)$ & \\
\hline ALK rearrangement & & & & 0.665 \\
\hline Negative & $84(93.3 \%)$ & $30(90.9 \%)$ & $54(94.7 \%)$ & \\
\hline Positive & $6(6.7 \%)$ & $3(9.1 \%)$ & $3(5.3 \%)$ & \\
\hline \multicolumn{5}{|l|}{ ROS1 rearrangement } \\
\hline Negative & $88(97.8 \%)$ & $33(100 \%)$ & $55(96.5 \%)$ & \\
\hline Positive & $2(2.2 \%)$ & $0(0 \%)$ & $2(3.5 \%)$ & 0.53 \\
\hline
\end{tabular}

progesterone negativity, Her2/Neu positivity, and higher rates of cell proliferation in breast cancer (25) and higher T stage with lymph node metastasis in gastric cancer (26). In clear cell renal cell carcinoma, PD-L1 expression was associated with higher Fuhrman nuclear grade $(27,28)$ as well as nonclear cell RCC patients (29). These findings suggest that PD-L1 might increase aggressiveness in cancer by escaping from host immune surveillance $(20,24)$.
This study had some limitations. First, it was a single institutional retrospective study using small biopsy specimens. Using $22 \mathrm{C} 3$ clone, $36.7 \%$ of cases showed PD-L1 expression (with $50 \%$ cut off value). This percentage was higher than that of previous reports using the same antibody platform on larger cohorts $(24.9 \%$ to $30.2 \%$ in advanced NSCLCs) (30-32). However, our results were obtained from small tissue samples of fine-needle aspirates. 
Yoon et al: PD-L1 Expression and Nuclear Features of NSCLC

Table II. Logistic regression analysis of the association of clinicopathologic variables with PD-L1 expression in tumor cells.

\begin{tabular}{lccc}
\hline Risk factor & Odds ratio & 95\% Confidence interval & $p$-Value \\
\hline Severe nuclear atypia & 1.828 & $0.433-7.730$ & 0.335 \\
Coarse chromatin pattern & 1.134 & $0.327-3.941$ & 0.609 \\
Predominant nucleoli & 6.688 & $1.784-25.065$ & $0.005^{*}$ \\
Large nuclear diameter & 1.115 & $0.247-5.031$ & 0.539 \\
Non-glandular feature & 4.539 & $1.508-13.663$ & $0.007^{*}$ \\
Atypical mitosis & 1.441 & $0.170-12.185$ & 0.702 \\
\hline
\end{tabular}

They might not represent the entire tumor PD-L1 expression. Two reports have described significant discordance in PD-L1 expression between biopsy specimens and corresponding resected specimens of NSCLC patients using the SP142 and SP263 clones $(9,33)$. Thus, further studies are needed in the future to determine PD-L1 expression in biopsy specimens and resected specimens using 22C3. Second, survival data could not be produced due to the short duration of follow-up. Third, PD-L1 immunohistochemistry was conducted using only one antibody. Recently, Kim $\mathrm{H}$ et al. have reported that positivity rates for PD-L1 were similar using assay-specific cut-offs and other antibodies such as 22C3, SP263, and SP142 (34). Studies using surgical specimens and other antibodies are needed to validate our findings.

In conclusion, this is the first investigation focusing on the relationship between nuclear features and PD-L1 expression in lung cancer. Our results demonstrated that PD-L1 expression was associated with worse nuclear features in univariate analysis. In multivariate analysis, prominent nucleoli and non-glandular feature were independent predictors of PD-L1 expression in lung adenocarcinoma. These results indicate that non-glandular feature and prominent nucleoli of adenocarcinoma might be good surrogate markers for PD-L1 expression in biopsy specimens.

\section{Conflicts of Interest}

The Authors declare no conflicts of interest regarding this study.

\section{Acknowledgements}

This research was supported by a Grant of Translational R\&D Project through Institute for Bio-Medical convergence, Incheon St. Mary's Hospital, The Catholic University of Korea.

\section{References}

1 Siegel R, Naishadham D and Jemal A: Cancer statistics, 2013. CA Cancer J Clin 63: 11-30, 2013.

2 Herbst RS, Soria J-C, Kowanetz M, Fine GD, Hamid O, Gordon MS, Sosman JA, McDermott DF, Powderly JD and Gettinger SN: Predictive correlates of response to the anti-PD-L1 antibody MPDL3280A in cancer patients. Nature 515: 563, 2014.
3 Shukuya T and Carbone DP: Predictive markers for the efficacy of anti-PD-1/PD-L1 antibodies in lung cancer. J Thorac Oncol 11: 976-988, 2016

4 Okazaki T and Honjo T: PD-1 and PD-1 ligands: from discovery to clinical application. Int Immunol 19: 813-824, 2007.

5 Brahmer JR, Tykodi SS, Chow LQ, Hwu W-J, Topalian SL, Hwu P, Drake CG, Camacho LH, Kauh J and Odunsi K: Safety and activity of anti-PD-L1 antibody in patients with advanced cancer. N Engl J Med 366: 2455-2465, 2012.

6 Topalian SL, Hodi FS, Brahmer JR, Gettinger SN, Smith DC, McDermott DF, Powderly JD, Carvajal RD, Sosman JA and Atkins MB: Safety, activity, and immune correlates of antiPD-1 antibody in cancer. N Engl J Med 2012: 2443-2454, 2012.

7 Gatalica Z, Snyder C, Maney T, Ghazalpour A, Holterman DA, Xiao N, Overberg $\mathrm{P}$, Rose I, Basu GD and Vranic S: Programmed cell death 1 (PD-1) and its ligand (PD-L1) in common cancers and their correlation with molecular cancer type. Cancer Epidemiol Biomarkers Prev 23: 2965-2970, 2014.

8 Pardoll DM: The blockade of immune checkpoints in cancer immunotherapy. Nat Rev Cancer 12: 252, 2012.

9 Munari E, Zamboni G, Marconi M, Sommaggio M, Brunelli M, Martignoni G, Netto GJ, Moretta F, Mingari MC, Salgarello M, Terzi A, Picece V, Pomari C, Lunardi G, Cavazza A, Rossi G, Moretta L and Bogina G: PD-L1 expression heterogeneity in non-small cell lung cancer: evaluation of small biopsies reliability. Oncotarget 8: 90123-90131, 2017.

10 Takada K, Okamoto T, Shoji F, Shimokawa M, Akamine T, Takamori S, Katsura M, Suzuki Y, Fujishita T and Toyokawa G: Clinical significance of PD-L1 protein expression in surgically resected primary lung adenocarcinoma. J Thorac Oncol 11: 1879-1890, 2016.

11 Dong ZY, Zhong WZ, Zhang XC, Su J, Xie Z, Liu SY, Tu HY, Chen HJ, Sun YL and Zhou Q: Potential predictive value of TP53 and KRAS mutation status for response to PD-1 blockade immunotherapy in lung adenocarcinoma. Clin Cancer Res 3(12): 3012-3024, 2017.

12 Roach C, Zhang N, Corigliano E, Jansson M, Toland G, Ponto G, Dolled-Filhart M, Emancipator K, Stanforth D and Kulangara K: Development of a companion diagnostic PD-L1 immunohistochemistry assay for pembrolizumab therapy in Non-small-cell lung cancer. Appl Immunohistochem Mol Morphol 24: 392, 2016.

13 Phillips T, Simmons P, Inzunza HD, Cogswell J, Novotny Jr J, Taylor $\mathrm{C}$ and Zhang X: Development of an automated PD-L1 immunohistochemistry(IHC) assay for non-small cell lung cancer. Appl Immunohistochem Mol Morphol 23: 541, 2015. 
14 Garon EB, Rizvi NA, Hui R, Leighl N, Balmanoukian AS, Eder JP, Patnaik A, Aggarwal C, Gubens $M$ and Horn L: Pembrolizumab for the treatment of non-small-cell lung cancer. N Engl J Med 372: 2018-2028, 2015.

15 Dolled-Filhart M, Roach C, Toland G, Stanforth D, Jansson M, Lubiniecki GM, Ponto G and Emancipator K: Development of a companion diagnostic for pembrolizumab in non-small cell lung cancer using immunohistochemistry for programmed death ligand-1. Arch Pathol Lab Med 140: 1243-1249, 2016.

16 Kadota K, Suzuki K, Colovos C, Sima CS, Rusch VW, Travis WD and Adusumilli PS: A nuclear grading system is a strong predictor of survival in epitheloid diffuse malignant pleural mesothelioma. Mod Pathol 25: 260-271, 2012.

17 Kadota K, Suzuki K, Kachala SS, Zabor EC, Sima CS, Moreira AL, Yoshizawa A, Riely GJ, Rusch VW and Adusumilli PS: A grading system combining architectural features and mitotic count predicts recurrence in stage I lung adenocarcinoma. Mod Pathol 25: 1117-1127, 2012.

18 Shimoji M, Shimizu S, Sato K, Suda K, Kobayashi Y, Tomizawa $\mathrm{K}$, Takemoto $\mathrm{T}$ and Mitsudomi $\mathrm{T}$ : Clinical and pathologic features of lung cancer expressing programmed cell death ligand 1 (PD-L1). Lung Cancer 98: 69-75, 2016.

19 Zhang Y, Wang L, Li Y, Pan Y, Wang R, Hu H, Li H, Luo X, Ye $\mathrm{T}$ and Sun $\mathrm{Y}$ : Protein expression of programmed death 1 ligand 1 and ligand 2 independently predict poor prognosis in surgically resected lung adenocarcinoma. Onco Targets Ther 7: 567, 2014.

$20 \mathrm{Ng}$ kee Kwong F, Laggner U, Mc Kinney O, Croud J, Rice A and Nicholson AG: Expression of PD-L1 correlates with pleomorphic morphology and histological patterns of non-small cell lung carcinomas. Histopathology 72: 1024-1032, 2018.

21 Yoshizawa A, Motoi N, Riely GJ, Sima CS, Gerald WL, Kris MG, Park BJ, Rusch VW and Travis WD: Impact of proposed IASLC/ATS/ERS classification of lung adenocarcinoma: prognostic subgroups and implications for further revision of staging based on analysis of 514 stage I cases. Mod Pathol 24: 653-664, 2011.

22 Amin MB, Tamboli P, Merchant SH, Ordóñez NG, Ro J, Ayala AG and Ro JY: Micropapillary component in lung adenocarcinoma: a distinctive histologic feature with possible prognostic significance. Am J Surg Pathol 26: 358-364, 2002.

23 Miyoshi T, Satoh Y, Okumura S, Nakagawa K, Shirakusa T, Tsuchiya E and Ishikawa Y: Early-stage lung adenocarcinomas with a micropapillary pattern, a distinct pathologic marker for a significantly poor prognosis. Am J Surg Pathol 27: 101-109, 2003.

24 Sterlacci W, Fiegl M, Droeser RA and Tzankov A: Expression of PD-L1 identifies a subgroup of more aggressive non-small cell carcinomas of the lung. Pathobiology 83: 267-275, 2016.

25 Sabatier R, Finetti P, Mamessier E, Adelaide J, Chaffanet M, Ali HR, Viens P, Caldas C, Birnbaum D and Bertucci F: Prognostic and predictive value of PDL1 expression in breast cancer. Oncotarget 6: 5449, 2015.

26 Qing Y, Li Q, Ren T, Xia W, Peng Y, Liu G-L, Luo H, Yang Y$\mathrm{X}$, Dai X-Y and Zhou S-F: Upregulation of PD-L1 and APE1 is associated with tumorigenesis and poor prognosis of gastric cancer. Drug Des Devel Ther 9: 901, 2015.
27 Thompson RH, Kuntz SM, Leibovich BC, Dong H, Lohse CM, Webster WS, Sengupta S, Frank I, Parker AS and Zincke H: Tumor B7-H1 is associated with poor prognosis in renal cell carcinoma patients with long-term follow-up. Cancer Res 66: 3381-3385, 2006.

28 Leite KR, Reis ST, Junior JP, Zerati M, de Oliveira Gomes D, Camara-Lopes LH and Srougi M: PD-L1 expression in renal cell carcinoma clear cell type is related to unfavorable prognosis. Diagn Pathol 10: 189, 2015.

29 Choueiri T, Fay A, Gray K, Callea M, Ho T, Albiges L, Bellmunt J, Song J, Carvo I and Lampron M: PD-L1 expression in nonclearcell renal cell carcinoma. Ann Oncol 25: 2178-2184, 2014.

30 Herbst RS, Baas P, Kim DW, Felip E, Perez-Gracia JL, Han JY, Molina J, Kim JH, Arvis CD, Ahn MJ, Majem M, Fidler MJ, de Castro G Jr., Garrido M, Lubiniecki GM, Shentu Y, Im E, Dolled-Filhart $\mathrm{M}$ and Garon EB: Pembrolizumab versus docetaxel for previously treated, PD-L1-positive, advanced nonsmall-cell lung cancer (KEYNOTE-010): a randomised controlled trial. Lancet 387: 1540-1550, 2016.

31 Reck M, Rodriguez-Abreu D, Robinson AG, Hui R, Csoszi T, Fulop A, Gottfried M, Peled N, Tafreshi A, Cuffe S, O'Brien M, Rao S, Hotta K, Leiby MA, Lubiniecki GM, Shentu Y, Rangwala R, Brahmer JR and Investigators K-: Pembrolizumab versus chemotherapy for PD-L1-positive non-small-cell lung cancer. N Engl J Med 375: 1823-1833, 2016.

32 Garon EB, Rizvi NA, Hui R, Leighl N, Balmanoukian AS, Eder JP, Patnaik A, Aggarwal C, Gubens M, Horn L, Carcereny E, Ahn MJ, Felip E, Lee JS, Hellmann MD, Hamid O, Goldman JW, Soria JC, Dolled-Filhart M, Rutledge RZ, Zhang J, Lunceford JK, Rangwala R, Lubiniecki GM, Roach C, Emancipator K, Gandhi L and Investigators K-: Pembrolizumab for the treatment of non-small-cell lung cancer. N Engl J Med 372: 2018-2028, 2015.

33 Ilie M, Long-Mira E, Bence C, Butori C, Lassalle S, Bouhlel L, Fazzalari L, Zahaf K, Lalvee S, Washetine K, Mouroux J, Venissac N, Poudenx M, Otto J, Sabourin JC, Marquette CH, Hofman V and Hofman P: Comparative study of the PD-L1 status between surgically resected specimens and matched biopsies of NSCLC patients reveal major discordances: a potential issue for anti-PD-L1 therapeutic strategies. Ann Oncol 27: 147-153, 2016.

34 Kim H, Kwon HJ, Park SY, Park E and Chung JH: PD-L1 immunohistochemical assays for assessment of therapeutic strategies involving immune checkpoint inhibitors in non-small cell lung cancer: a comparative study. Oncotarget 8: 9852498532, 2017. 